\title{
Review Modeling of Solid Waste Transportation Routes Using Geographical Information System (GIS)
}

\author{
Dian Haerani ${ }^{1, *}$, Syafrudin ${ }^{2}$, Sasongko Setia Budi ${ }^{3}$ \\ ${ }^{1}$ Master Program of Environmental Science, Diponegoro University, Semarang - Indonesia \\ ${ }^{2}$ Department of Environmental Engineering, Faculty of Engineering, Diponegoro University, Semarang - Indonesia \\ ${ }^{3}$ Department of Chemical Engineering, Faculty of Engineering, Diponegoro University, Semarang - Indonesia
}

\begin{abstract}
Waste transportation is a part of complex waste management. Waste transportation will be influenced by the growth of waste. To simplify the implementation of garbage transportation, a waste transportation model is needed. Various wastes transportation models have been developed to explain the process of transporting garbage. The garbage transport model is basically designed to simplify the transportation system so that the behavior of several components in the system can be known. One of the models that can be used in the garbage transportation system is GIS. GIS is a spatial and computerized waste-based modeling, so in era 4.0 this modeling of waste transportation using GIS was needed. This paper aims to discuss the modeling of waste transportation using GIS has been carried out in various regions. The discussion of the paper discusses the use of GIS in waste transportation, a factor that influences GIS in waste transportation.
\end{abstract}

Keywords: solid waste; collecting; solid waste collecting modeling; GIS.

\section{Introduction}

According to UU no 18 year 2008 regarding about Waste Management, Solid Waste is the remainder of everyday human activities and/or natural processes that are in solid form. Solid waste identically as a material or item that is useless and cannot be used again.

The emergence of solid waste problems is triggered by the imbalances between the amount of waste generation with waste management and decreased carrying capacity of the environment in accommodating waste disposal. Waste production is getting out of control, but the ability to waste management is still inadequate. The unmanaged increase in waste will have a chain effect on the environment in the form of pollution, disease transmission, odor, inhibiting the flow of water in drainage channels and rivers and impacting the aesthetics of urban beauty[1]. The imbalance in the amount of waste generation and waste management efforts has resulted in the level of waste services not being optimal [2].

Waste management is all processes and activities to manage waste so as not to have an impact on the environment carried out thoroughly and sustainably. Waste management consists of the process of reducing waste and waste handling [3]. Operational techniques in waste management include waste collection, accumulation, transportation, waste processing and final processing (landfill) [4].

Transportation of waste is included in transportation because in the transportation of garbage there is a process of moving goods (in this case garbage) from one place to another (from TPS to TPA) [5].

\section{Solid Waste Transportation}

In waste management, there is one important aspect that influences the waste transportation activity. Waste transportation is a waste management operational activity that starts from the last garbage collection location (TPS, TPS 3R, Transfer Depo) to TPA [6, 7].

The problem of transporting solid waste is due to the low frequency of transportation, the length of the waste transportation route, the inappropriate capacity of the transport vehicle, and the length of time for the transportation of solid waste. This has an impact on the amount of waste transported and the level of waste services [6].

The level of waste transportation is influenced by several factors like the vehicles of transporting garbage, the amount of trash will be transported and the operational costs of garbage handling [8].

Currently, solid waste is still a global problem that must be solved. Waste problems generally occur in urban areas. Along with the increase in the number of the people it will have an impact on increasing waste generation so that the management of urban waste management must be the main focus in city authority and planning [9].

Solid waste transportation is a part of difficult and complex waste management due to the increasing

* Corresponding author: dierazena@gmail.com 
production of garbage at the residential, commercial, road, etc [10]. Tchobanoglous \& Kreith [11], Sahoo et.al [12] states that it is estimated that around $50-70 \%$ of the total cost of waste management (collection, transportation, processing, recycling, and destruction) is the cost of operating waste transportation. Inefficiently transporting solid waste will have the following impacts:

1. There are still many remnants of non-transported waste. This will further have a negative impact on public health [13].

2. The low rate of rehabilitation that has been carried out so far has caused a large operational cost.

3. It can reduce operational time in the process of sweeping and scavenging waste carried out by transport officers if the route has been optimized.

4. Wastes are disposed of carelessly in ditches, ditches, water bodies (rivers and lakes) or even the amount of burning of solid waste by the community

\subsection{Solid waste transportation Method}

The collection/transportation process does not only cover garbage collection from various sources but also transports waste to locations where the contents of collecting vehicles are emptied and the collection of collecting vehicles is demolished [14]. Generally, transport of solid waste can be carried out using the following method : [11]

1) Hauled Container System (HCS)

Hauled Container System (HCS) or known as carried container method is the method of solid waste transporting where the garbage collection container will move along and be transported/taken to the final disposal site. The method usually uses containers as collection containers and is commonly used for commercial areas or populous residential types.

2) Stationary Container System (SCS)

Stationary Container System (SCS) or the container housing method is a method of solid waste transporting waste where the collecting container is left or not carried along with the transport vehicle. Generally, the collecting container used in this method is a container that is easily lifted or cannot be lifted and this method is commonly used in regular residential areas.

To get an efficient and effective transportation system, waste transportation operations should follow the procedure as follows:

- Use the transport route as short as possible and with the smallest possible obstacles.

- Using a transport vehicle with a maximum capacity/carrying capacity.

- Using a fuel-efficient transport vehicle.

- Can take full advantage of work time by increasing the amount of workload as much as possible by increasing the number of workloads/transportation rites.

The pattern of waste transportation that is commonly used in Indonesia includes : [4]

1. The pattern of direct transport of individual waste;
2. Indirect individual waste transportation patterns;

3. A pattern of direct communal waste transportation;

4. The pattern of indirect communal waste transportation;

5. Street sweeping patterns

The challenge of waste transport research is the need for basic data analysis of waste transportation and the application of a suitable waste transportation model for each region.

This article is a review of waste transportation modeling using GIS. The review begins by describing the waste transport modeling that has been carried out, then explains the definition of GIS, the advantages of using GIS in transporting waste, the factors that influence waste transportation modeling using GIS and the stage in carrying out waste transportation modeling.

The method carried out in this review is to explain the garbage transport modeling that has been done by other writers in various regions both in Indonesia and outside country. Presentations are taken from several relevant journal articles in the past 10 years.

\section{Solid Waste Collecting Model}

There are several models of solid waste transport routes that have been examined, including:

\subsection{Travelling Salesman Problem (TSP)}

The actual TSP case model is that there is a salesman who will visit a number of cities. However, all cities must be visited and each city can only be visited exactly once. The problem is how the salesman can determine the shortest route that will be traversed in visiting the entire city and back to the initial city [15].

The thing that needs to be considered in the TSP case is the journey of the salesman starting from the beginning of the city to the next to the city and finally going back to the initial city. However, the rule is that every city other than the initial city can only be visited exactly once. The problem faced is how to build optimal route lines by considering these rules in order to obtain a minimum total mileage so that it will have an impact on savings transport costs [16].

\subsection{Genetic Algorithms}

Genetic algorithms are one branch of computer science in the field of artificial intelligence for optimization techniques. This algorithm adopts the biological mechanism proposed by Charles Darwin with his famous and controversial evolutionary theory. Some examples of the application of genetic algorithms are in the industrial field for determining machine layout [17]. Furthermore, genetic algorithms can be applied to the field of animal husbandry for determining the composition of animal feed, and in the field of civil engineering can be applied to design pipeline distribution lines. Thus genetic algorithms look quite capable of solving problems of optimization universally. 
Genetic Algorithms can be used to solve searching and optimization problems that have high complexity that occur a lot in dynamic programmings such as TSP and Knapsack Problem. In schematic genetic algorithms, each element must be modified for each specific problem, such as the selection of methods that represent solutions, which is each operator must define [18].

\subsection{Vehicle Routing Problem (VRP)}

Routing Problem (VRP) as a range of problems with a number of routes and a number of vehicles that are in one or several depots that must be determined so that they can serve all consumers in several cities [19]. The problem of vehicle routes is a common problem because each vehicle must travel in the study area and visit all trash bins [20], does not have a time limit when to start and stop at a service at a different node. this is contrary to scheduling containing the time, must be repaired first, and services at each node must be completed [16]. This modeling is generally used to minimize the total cost of travel, but most often is distance or time but also fuel consumption, $\mathrm{CO} 2$ emissions, etc [20].

Generally, the type of solid waste transport modeling above does not carry out spatial mapping of the location of waste transport areas, spatial mapping of collection container locations, TPS and landfill.

\section{Waste Collecting Model Using GIS}

Geographical Information System (GIS) modeling has been developed and used as a support tool in waste transportation in recent years because of technological developments and increasing proportions and the complexity of spatial information [21] and in accordance with the era of technology 4.0. Transporting waste using spatial modeling and GIS can give benefits for the environment and significant economic savings such as travel time reduction, distance, fuel consumption, and pollutant emissions [20, 22, 23].

GIS is one of the most sophisticated and modern technologies for capturing, storing, manipulating, analyzing, and displaying spatial data. In GIS, data is usually arranged in thematic layers and in the form of digital maps [24]. The hardest section from GIS analysis is finding out the tools can be used to solve the GIS problem.

At present, integrated GIS technology has been approved as one of the most promising systems to automate the planning process and managing waste [25]. Waste management that often uses GIS modeling applications is the landfill area and optimization of waste collection and transportation.

Analyzing the collection and scheduling routes of collection vehicles in the road networks taking into account economic goals and equalization can be complicated. GIS makes it possible to create and store as many data layers or maps. GIS can also provide several possibilities for integrating a very large number of data and mapping layers into one output to assist in decision making. Advances in GIS technology make it possible to carry out complex analyses [26].

In a solid waste transportation system, detailed spatial information will be needed. The information relates to the geographical of the study area data, including spatial data the garbage transportation system. Data needed include population density, waste generation, storage (number, type, and position), road network and existing garbage transportation routes, garbage truck capacity and transportation patterns used [27].

Network analysis is part of GIS modeling and includes a special type of line analysis that involves a series of interconnected paths, covering themes such as roads, flows, natural pathways, and pipelines. Analysis that can be done using network analysis includes : [28, 29]

1) Geocoding Address.

Address geocoding is the process of retrieving an address and then estimating its place in the GIS coordinate system. This process to connect the address database with GIS. Examples of the use of this analysis are displaying the home address on the GIS road display, generating travel directions to the address provided, or displaying the location of facilities and infrastructure in the form of a GIS display based on a list of facilities and infrastructure addresses.

2) Optimal Routing.

Optimal routing is a process to describe the best route on a journey from one location to another. "The best route" can be the shortest, fastest, or most aesthetic route, based on the preferences of GIS users in defining "best." An example of this application is determining the fastest way to go from the fire station to the fire location, determine the shortest route for the water channel or determine the most economical shipping route to several stops.

3) Finding Nearby Facilities.

This analysis is a special analysis of optimal routing. In this analysis where to find the closest point to a particular location. Usually, these points are called facilities and locations provided. Examples of this analysis are determining two fire stations that have the best response time for the fire incident reported, determining the best ambulance station to respond to incident reports, or finding ten houses for sale that are closest to the childcare center.

4) Resource Allocation.

Resource allocation is the process of allocating resources from the supply center to customers on a network. Examples of this analysis are the amount of water that supplies wells to irrigation networks, etc. In this process, resources are usually allocated throughout the network until the resources run out, or requests across the network are met.

Factors that influence the transportation of waste using GIS are maps of the region (city), type of collection container, location of polling stations, transportation routes and road networks, and landfill locations $[7,13,30]$. 


\section{a. Maps Of The Region (City)}

The area and the number of people who are the objects of garbage transportation affect the growth of garbage, the type of container collection of garbage, the extent of the transportation route of waste, the point of transportation, the type of vehicle used for transporting garbage [20].

\section{b. Type Of Collection Container}

The type of garbage collection container will affect the waste transportation process both the collection time and the collection frequency. Different types of garbage collection containers will take time and frequency of different waste transports [7]. Generally, the types of garbage collection containers are in the form of barrels, containers, plastic bags, and so on.

\section{c. Location Of Polling Stations}

The determination of waste transport points is based on the conditions of the people served. The point of transportation of waste can be in the form of TPS, depo transfers, settlements. The point of transporting waste will affect the type of vehicle used, the transportation route and the frequency of garbage transportation [7].

\section{d. Transportation Routes And Road Networks}

The road network (road type and road conditions) in an area will affect the trash transportation route. The garbage transportation route is influenced by the distance of the waste transportation location, the time of garbage collection and the frequency of transportation. The closer the distance of a garbage transport route will be the faster the process of collecting and transporting garbage. However, the road network that is not good but has a short distance is not included in the efficient cutaneous route.

\section{e. Landfill Locations}

The landfill location (TPA) influences the garbage transportation route. The shortest trash routing route with TPA will be prioritized to be chosen, but the condition of the road network is still being analyzed.

Modeling using GIS requires software namely ArcMap, which has the ability to enter and store geographical (coordinate) and tabular (attribute) data, to find specific features based on location related to interactions between several data sets, to describe geographical features. Results obtained from ArcMap include various formats such as maps and graphics [7]. Things done in modeling waste transportation using GIS include:

1) Photographing the conditions of waste management and transportation of waste in an area, which includes: types of garbage collection containers, types of garbage transport vehicles, mapping of settlement locations, commercial buildings and city facilities (schools, mosques, etc.), location of polling stations and placement of containers, landfill locations (TPA) [25].

2) Designing spatial data includes Road network, street address/name, location of trash, population density, land use and map of the area [25].

3) Analysis of transport routes using GIS. this analysis uses Network Analysis on GIS. Spatial data that has been designed is then analyzed with the Network Analysis tools so that an efficient transport route can be obtained. On the Network Analysis tool, data can be entered on traffic density so that roads that experience density can be avoided for trash transport routes [31].

\section{Conclusion}

Waste transportation including difficult and complicated waste management. There are several models that can be used to make garbage transportation routes, but modeling that is considered suitable for use in era 4.0 is modeling using GIS. GIS is a model that can map natural conditions that exist and occur today. By using GIS, spatial data will be obtained that matches the original conditions and can be analyzed again if the efficient conditions are outdated. to produce a garbage transport model using good GIS, accurate spatial data is needed, such as the distance of landfill location, distribution of polling stations, traffic congestion conditions, etc. In the current era of technology 4.0, the use of GIS as a modeling tool is the right choice and needs to be applied in various regions so that actual conditions can be mapped and analyzed spatially.

\section{References}

1. K. Joseph, S. Rajendiran, R. Senthilnathan, M. Rakesh, J. Mater, Cycles Waste Manag. 14, 75 (2012)

2. S. Tato, 65 (2011)

3. UU No. 18 (2008)

4. SNI 19-2454-2002 (2002)

5. A. Munawar, S. Priyanto, M.Z. Irawan, Pengantar Teknik Transportasi, Universitas Gajah Mada, Yogyakarta (2018)

6. sanitasi.net (2019)

7. A. Khajuria, T. Matsui, T. Machimura, Our Nat. 9, 26 (2011)

8. K. Subur, A. Wilujeng, H.S. Titah, Pros. Semin. Nas. Manaj. Teknol. III (2006)

9. M. Khan, M. Vaezi, A. Kumar, Sci. Total Environ. 610-611, 1065 (2018)

10. A. Malakahmad, N.D. Khalil, Int. Conf. Business, Eng. Ind. Appl., 174-179 (2011)

11. G. Tchobanoglous, F. Kreith, Handbook of Solid Waste Management, second McGraw-Hill, New York (2002)

12. S. Sahoo, S. Kim, B.I. Kim, B. Kraas, A. Popov, Interfaces (Providence) 35, 24 (2005)

13. T.E. Kanchanabhan, J.A. Mohaideen, S. Srinivasan, V.L.K. Sundaram, Waste Manag. Res. 29, 323 (2011)

14. G. Tchobanoglous, H. Theisen, S.A. Vigil, Integrated Solid Waste Management, Enggineering Principles and Management Issues, McGraw-Hill, New York (1993)

15. Y. Sukarmawati, Nahry, D.M. Hartono, J. Transp. 13, 1 (2013)

16. D. Teodorovic, M. Janic, Transportation 
Engineering, Joe Hayton (2017)

17. M.D.A.C. Hasibuan, Lusiana, Sains dan Teknol. Inf. 1, (2015)

18. J. Bautista, J. Pereira, Omega 34, 617 (2006)

19. H. Hadi, (2016)

20. C. Chalkias, K. Lasaridi, WSEAS Trans. Environ. Dev. 5, 640 (2009)

21. L. Santos, J. Coutinho-Rodrigues, J. Current, Transp. Res. Part A Policy Pract. 42, 922 (2008)

22. O.M. Johansson, Waste Manag. 26, 875 (2006)

23. G. Tavares, Z. Zsigraiova, V. Semiao, M. Carvalho, Manag. Environ. Qual. 19, 444 (2008)

24. C. Chalkias, K. Lasaridi, Integr. Waste Manag., diedit oleh S. Kumar (InTech, Rijeka), 417-436 (2011)

25. N.V Karadimas, V.G. Loumos, Waste Manag. Res. 26, 337 (2008)

26. N.-B. Chang, H.Y. Lu, Y.L. Wei, J. Environ. Eng. 123, 901 (1997)

27. R. Hidayat, J. Wil, Lingkung. 1, 201 (2013)

28. D.L. Verbyla, Practical GIS Analysis, Taylor \& Francis, New York (2002)

29. A. Bhambulkar, Int. J. Adv. Eng. Sci. Technol. 11, $202(2011)$

30. H.L. Vu, K.T.W. Ng, D. Bolingbroke, Waste Manag. 78, 258 (2018)

31. J. Lella, V. Ravibabu, X. Zhu, Sustain. Cities Soc. 35, 336 (2017) 